\title{
Generating fuzzy rules by learning from olive tree transpiration measurement - An algorithm to automatize Granier sap flow data analysis
}

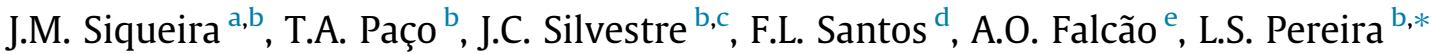 \\ ${ }^{a}$ CSF Program, CAPES Foundation, Ministry of Education of Brazil, Brazil \\ ${ }^{\mathrm{b}}$ CEER, Biosystems Engineering, Instituto Superior de Agronomia, Universidade de Lisboa, Tapada da Ajuda, 1349-017 Lisboa, Portugal \\ ' Instituto Nacional de Investigação Agrária e Veterinária, Dois Portos, Portugal \\ d Instituto de Ciências Agrárias e Ambientais Mediterrânicas, Universidade de Évora, Évora, Portugal \\ e Departamento de Informática, Faculdade de Ciências, Universidade de Lisboa, Portugal
}

\section{A R T I C L E I N F O}

\section{Article history:}

Received 12 July 2013

Received in revised form 21 October 2013

Accepted 26 November 2013

\section{Keywords:}

Fuzzy rule

Machine learning

Sap flow measurement

Plant transpiration

Granier method

\begin{abstract}
A B S T R A C T
The present study aims at developing an intelligent system of automating data analysis and prediction embedded in a fuzzy logic algorithm (FAUSY) to capture the relationship between environmental variables and sap flow measurements (Granier method). Environmental thermal gradients often interfere with Granier sap flow measurements since this method uses heat as a tracer, thus introducing a bias in transpiration flux calculation. The FAUSY algorithm is applied to solve measurement problems and provides an approximate and yet effective way of finding the relationship between the environmental variables and the natural temperature gradient (NTG), which is too complex or too ill-defined for precise mathematical analysis. In the process, FAUSY extracts the relationships from a set of input-output environmental observations, thus general directions for algorithm-based machine learning in fuzzy systems are outlined. Through an iterative procedure, the algorithm plays with the learning or forecasting via a simulated model. After a series of error control iterations, the outcome of the algorithm may become highly refined and be able to evolve into a more formal structure of rules, facilitating the automation of Granier sap flow data analysis. The system presented herein simulates the occurrence of NTG with reasonable accuracy, with an average residual error of $2.53 \%$ for sap flux rate, when compared to data processing performed in the usual way. For practical applications, this is an acceptable margin of error given that FAUSY could correct NTG errors up to an average of $76 \%$ of the normal manual correction process. In this sense, FAUSY provides a powerful and flexible way of establishing the relationships between the environment and NTG occurrences.
\end{abstract}

(c) 2013 Elsevier B.V. All rights reserved.

\section{Introduction}

The need for improved irrigation management and better understanding of plant water relations led to the development of several methods for estimating water flow in plant stems. The whole plant transpiration can be estimated by sap flow measurement methods. The heat dissipation method is one of those methods that performs a direct measurement in a trunk section using simple physical principles. This method is often identified as the Granier method (Granier, 1985; Lu et al., 2004; González-Altozano et al., 2008).

The Granier method bases upon the heat flux provided by means of an adjustable source of electrical energy and constant power through a probe inserted in the trunk, which is correlated

\footnotetext{
* Corresponding author. Tel.: +351 213 653339; fax: +351 213653287

E-mail address: Ispereira@isa.utl.pt (L.S. Pereira).
}

to the heat removed by sap flow. For this purpose, two probes are used to determine the temperature difference $\left(\Delta T,\left[{ }^{\circ} \mathrm{C}\right]\right)$ between the upper heating point and an unheated probe placed in a lower point. The $\Delta T$ value is introduced into the equation:

$k=\left(\Delta T_{\max }-\Delta T\right) / \Delta T$

where $\Delta T_{\max }$ is the maximum value of $\Delta T$ and $k$ is the flux index. The flux is calculated from $k$ with a relationship admitted to be species independent (Granier, 1985; Granier et al., 1990; Valancogne and Granier, 1997) based on empirical calibrations:

$u=118.99 \times 10^{-6} k^{1.231}$

where $u$ is the sap flux density $\left[\mathrm{m}^{3} \mathrm{~m}^{-2} \mathrm{~s}^{-1}\right]$. On a daily course, the maximum temperature difference $\Delta T_{\max }$ between both probes in a sensor indicates the minimum or null sap flux rate for that specific day. The sap flux $F\left[\mathrm{~m}^{3} \mathrm{~s}^{-1}\right]$ can be calculated as:

$F=u \cdot A$ 


\section{Nomenclature}

A area of the conducting xylem section $\left(\mathrm{m}^{2}\right)$

$a_{j}, b_{j}$ and $c_{j}$ parameters of a triangular membership function for the $j_{\text {th }}$ FS

DOY day of year

e event

$E T_{0} \quad$ reference evapotranspiration

$F \quad$ sap flux $\left(\mathrm{m}^{3} \mathrm{~s}^{-1}\right)$

$F_{a d j} \quad$ adjusted sap flux $\left(\mathrm{m}^{3} \mathrm{~s}^{-1}\right)$

$f_{c} \quad$ fraction of ground covered by vegetation

$F_{n a} \quad$ not adjusted sap flux $\left(\mathrm{m}^{3} \mathrm{~s}^{-1}\right)$

$F_{\text {pred }} \quad$ predicted sap flux $\left(\mathrm{m}^{3} \mathrm{~s}^{-1}\right)$

$\mathrm{FS}_{\mathrm{j}} \quad$ fuzzy set

FV explicative fuzzy variables

$f_{w} \quad$ fraction of soil surface wetted by irrigation

$f_{\Delta j} \quad$ triangular membership function

GN reference sensor

$k \quad$ flux index (Granier coefficient)

$k_{a d j} \quad$ adjusted flux index (Granier coefficient)

$k_{n a} \quad$ not adjusted flux index (Granier coefficient)

$k_{\text {pred }} \quad$ predicted flux index (Granier coefficient)

MSE mean square error

$n_{f r} \quad$ number of fuzzy regions

$\mathrm{NTG}_{\text {pred }(t)}$ NTG predicted via algorithm at $t$ time $\left({ }^{\circ} \mathrm{C}\right)$

NTG natural temperature gradient $\left({ }^{\circ} \mathrm{C}\right)$

$\mathrm{NTG}_{o b s(t)}$ observed temperature difference of GN at $t$ time $\left({ }^{\circ} \mathrm{C}\right)$

PFC the percentage of FAUSY contribution (\%)

RE residual error
$\mathrm{RE}_{\mathrm{f}} \quad$ residual error of sap flux predicted $\left(\mathrm{m}^{3} \mathrm{~s}^{-1}\right)$

$\mathrm{RE}_{\mathrm{na}} \quad$ residual error of sap flux not adjusted $\left(\mathrm{m}^{3} \mathrm{~s}^{-1}\right)$

$\mathrm{RH} \quad$ relative humidity (\%)

$R_{S} \quad$ solar radiation $\left(\mathrm{W} \mathrm{m}^{-2}\right)$

$t \quad$ time variable.

Time fraction of day $(1 / 48,12 / 48, \ldots, 48 / 48))$ variable

$u \quad$ sap flux density $\left(\mathrm{m}^{3} \mathrm{~m}^{-2} \mathrm{~s}^{-1}\right)$

$u_{a d} \quad$ adjusted sap flux density $\left(\mathrm{m}^{3} \mathrm{~m}^{-2} \mathrm{~s}^{-1}\right)$

UD universe of discourse

$u_{n a} \quad$ not adjusted sap flux density $\left(\mathrm{m}^{3} \mathrm{~m}^{-2} \mathrm{~s}^{-1}\right)$

$u_{\text {pred }} \quad$ predicted sap flux density $\left(\mathrm{m}^{3} \mathrm{~m}^{-2} \mathrm{~s}^{-1}\right)$

$\mathrm{Vd}$ the output relative to each event $e$

$x \quad$ actual value of a variable

$x_{\max } \quad$ maximum normalized value of a variable

$x_{\min } \quad$ minimum normalized value of a variable

$x_{n} \quad$ normalized value of a variable

$\Delta T_{n a(t)} \quad$ not adjusted temperature difference at $t$ time $\left({ }^{\circ} \mathrm{C}\right)$

$\Delta T \quad$ temperature difference $\left({ }^{\circ} \mathrm{C}\right)$

$\Delta T_{(t)} \quad$ temperature difference at $t$ time $\left({ }^{\circ} \mathrm{C}\right)$

$\Delta T_{\text {adj(t) }} \quad$ adjusted temperature difference at $t$ time $\left({ }^{\circ} \mathrm{C}\right)$

$\Delta T_{\max } \quad$ maximum temperature difference $\left({ }^{\circ} \mathrm{C}\right)$

$\Delta T_{\text {max_adj }}$ maximum adjusted temperature difference $\left({ }^{\circ} \mathrm{C}\right)$

$\Delta T_{\text {max } \_ \text {na }}$ maximum not adjusted temperature difference $\left({ }^{\circ} \mathrm{C}\right)$

$\Delta T_{\text {pred }(t)}$ predicted temperature difference at $t$ time $\left({ }^{\circ} \mathrm{C}\right)$ where $A$ is the area $\left[\mathrm{m}^{2}\right]$ of the conducting xylem section. This method has been successfully used in numerous studies, including in Portugal (Ferreira et al., 2004; Silva et al., 2008; Paço et al., 2009, 2012).

In theory, the Granier method is functional and measurements are easily automated. However, it requires heavy data processing and analysis for its systematic use while these tasks are difficult to automate (Do and Rocheteau, 2002a; Bush et al., 2010) since they require frequent user intervention. Beyond, it is assumed that the temperature measurements are not changed by the occurrence of natural temperature gradients $\left(\mathrm{NTG},\left[{ }^{\circ} \mathrm{C}\right]\right)$ in the trunk. Nonetheless, a NTG occurrence is easily verified by turning off the probe heating. The NTG are most likely originated by factors such as the azimuth of the probes inserted into the trunk, the distance between probes and the effect of radiation, soil and air temperature in the vicinity of the trunk. The variations of the $\Delta T$ circadian curve induced by the NTG contribute to errors in $\Delta T_{\max }$ and consequently in sap flux calculation since the error is propagated to $k$. These errors are difficult to be detected and corrected in automatic calculus (Lu et al., 2004; Allen et al., 2011); thus, the process frequently needs a human decision, which constitutes an obstacle to automation. This is particularly pertinent for long temporal series.

Correction techniques for Granier sap flow measurements have been applied in order to eliminate or reduce inaccuracy introduced by NTG (Lundblad et al., 2001; Regalado and Ritter, 2007). Two general methodologies are referred in literature: the shutdown of the heating probe during specific periods (Lundblad et al., 2001; Do and Rocheteau, 2002a; Silva et al., 2008) and the use of unheated probes specifically for this purpose (Köstner et al., 1998). Cabibel and Do (1991) proposed a more elaborated correction method, which involves correlations between natural gradients for each probe and micrometeorological measurements. A temperature measurement close to the heated and unheated points, but apart enough to avoid any interference with the heat source, can also be performed as a proxy to infer NTG (Cermák and Kucera, 1981). However, this is not exact information since the measurement points do not coincide. The correction methods mentioned above are usually adequate to specific applications, but do not provide a universal adjustment. The NTG is spatial and temporally variable, not only changing among different trees but also when different sensor installations are used in the same tree. The alternative of combining switched on and switched off sensors to remove NTG bias is limited because it requires that the NTG variability around the trunk is negligible, which is occasional in practice, and that the heating sensor does not affect the NTG occurrences, meaning that the method is restricted to large trees only (Lu et al., 2004). Do and Rocheteau (2002b) tested a new measurement approach employing cyclic heating just in particular situations, where significant natural temperature gradients $\left(\mathrm{NTG}>0.2^{\circ} \mathrm{C}\right.$ ) are expected and the residual error is possibly diluted. Beyond that, this solution delivers a lower time resolution, needs more expensive equipment to provide for cyclic heating and makes the system far more complex. Additionally, Lubczynski et al. (2012) concluded that the cyclic method in its current state of implementation is not yet optimized with respect to species and variability of environmental conditions, and that data processing is also not fully automated.

Recently, Vandegehuchte and Steppe (2013) reported the Granier method as being the most cited concerning NTG occurrence, contrarily to other methods where the influence of NTG on measurements has not been reported yet (e.g., heat field deformation method, Nadezhdina et al., 1998, 2012), although it is expected to be smaller, given the shorter distances to the heat source. Corrections have also been suggested for the tissue heat balance (THB) method (Cermák et al., 1973, Kucera et al., 1977) as reported by Köstner et al. (1998) but Tatarinov et al. (2005) have further 
concluded that the small heat field generated by the Granier method turns it more sensitive than the THB technique to NTG, among other factors. Köstner et al. (1998) also report that heat pulse velocity methods are, in their turn, less prone to thermal imbalances than heat balance methods.

An improved solution to overcome the difficulties arising from the existence of NTG and a generalization of the process would be useful. Furthermore, it would be beneficial to find relationships between NTG and environmental variables to help increase the accuracy of NTG determination and its potential automation. Concerning the relationship between NTG and environmental conditions, Do and Rocheteau (2002a) observed that the magnitude and variability of NTG were likely exacerbated by the combination of open stand, high solar radiation and low sap flow rate. Gutiérrez et al. (1994) have also observed that large temperature differentials in the environment and conditions leading to a high radiation load on an exposed stem may adversely affect the accuracy of the Granier technique, particularly if the gauge is not appropriately insulated and shielded. Those authors minimized the rate of change in stem temperature by additional stem insulation.

Automatic and universal correction methods accounting for NTG require specific algorithms capable of (a) processing high quantity of data, (b) picking up relationships with environmental parameters, and (c) being smart enough to mimetize human decision capabilities, requiring appropriate treatment of data in order to obtain useful information and processing techniques. Such an algorithm could be a relational fuzzy algorithm (Delgado et al., 2009) developed by means of fuzzy rules, understood as an alternative method to treat models with approximate or inexact reasoning, generalizing and making data processing faster and accurate, then becoming an important tool for approximate analysis of systems and decision processes, that are much too complex for the application of conventional mathematical techniques ( $\mathrm{Za}$ deh, 1965, 1968, 1973, 2009). The fuzzy algorithm based on automatic fuzzy inference must stand computational simplicity and flexibility, aiming at being embedded within the measurement device to support the model parameterization (Siqueira and Rocio, 2011).

The concepts of fuzzy logic can be used to translate into mathematical language the approximate information contained in sentences expressed in natural language inserted into the system. This is done by simplifying, selecting or rejecting simulations and generating a restricted set of parameter solutions or linearizing a mathematical model. Fuzzy logic has been widely applied in agricultural studies (e.g., Passam et al., 2003; Mustafa, 2009; Huang et al., 2010). Also, Tzimopoulos et al. (2008) estimated potential evapotranspiration with a fuzzy logic approach; the model was driven by fuzzy reasoning with the system through learning from observed temperature and evapotranspiration, with results compared with those of the Blaney-Criddle method. Odhiambo and Yoder (2001) showed that fuzzy evapotranspiration (ET) models can achieve accurate estimation of daily reference ET, comparable to the FAO Penman-Monteith equation, with advantages over other methods. Keskin et al. (2004) developed fuzzy models to estimate daily pan evaporation based on meteorological data for Lake Eğirdir and compared with the Penman method. Casper et al. (2007) introduced a system based on a fuzzy rules approach and used soil moisture and precipitation as input variables to predict flow rates at the outlet of a watershed. Similarly, a rule-based fuzzy logic crop water stress index was developed using growth chamber data and was successfully tested on tall fescue grown in a greenhouse (AlFaraj et al., 2001). De La Torre et al. (2005) used a computational tool Predictive Fuzzy Rules Generator (PreFuRGe) based on fuzzy logic and data mining to investigate the optimal strawberry production in relation to nitrate concentration, in soil water at different depths, and determined the optimal fertilizer dose that allows equilibrium between production and minimized environmental damage. Kim et al. (2008) developed a fuzzy logic control algorithm to compensate for illumination variation and to achieve a consistent image from a sensor used for in-field plant sensing. The referred studies show the scientific relevance of fuzzy logic when applied to agricultural and environmental issues.

This paper suggests a fuzzy algorithm to linearize the biased data automatically and in real time, thus allowing the correction of NTG in plant transpiration measurements. In addition, the algorithm is expected to smooth the input of resulting transpiration values into the SIMDualKc model (Rosa et al., 2012) used for water balance and ET calculations. The integration of time series and optimization techniques, using means of learning from the environment in present and past time, is expected to obtain an innovative automatic data processing for the Granier method applied to olive trees.

\section{Materials and methods}

\subsection{Data acquisition}

The present study has used a dataset acquired by sap flow sensors inserted in tree trunks of a commercial olive grove located in Alentejo, Southern Portugal $\left(38^{\circ} 24^{\prime} \mathrm{N}, 7^{\circ} 43^{\prime} \mathrm{W}, 143 \mathrm{~m}\right.$ a.s.l.), during 61 days in 2012 (day of year (DOY) 100-160). Climate is dry subhumid, of Mediterranean type, with a dry and hot summer, an average annual rainfall of $600-800 \mathrm{~mm}$, most of it falling in autumn and winter, and average monthly temperatures varying from $9{ }^{\circ} \mathrm{C}$ in January to $24^{\circ} \mathrm{C}$ in July. The production system in the site, an olive grove of the cultivar Arbequina explored by the commercial farm "Olivais do Sul", uses a "super high density" management technique, adopting a high density of tree planting $(1.35 \mathrm{~m} \times 3.75 \mathrm{~m})$. The olive grove was irrigated nearly daily during spring and summer, with a drip system having emitters with discharge of $2.3 \mathrm{~L} \mathrm{~h}^{-1}$ and $0.75 \mathrm{~m}$ spacing along the row. This resulted in average irrigation daily amounts close to $3 \mathrm{~mm} \mathrm{~d}^{-1}$ during the irrigation season. The fraction of soil surface wetted by irrigation was $f_{w}=0.21$ and the fraction of ground covered by vegetation was $f_{c}=0.35$. The topography is undulated. The experimental plot is part of a large olive grove of approximately 78 ha. An automatic weather station (Pessl Instruments, model iMETOS Avr, Austria), located at about $12 \mathrm{~km}$ distance to the north-northwest direction, was used to collect meteorological data. Meteorological data was also used to compute reference evapotranspiration $\left(E T_{o}\right)$ following Allen et al. (1998). From these data, air temperature $\left(T,\left[{ }^{\circ} \mathrm{C}\right]\right)$ relative humidity $(R H,[\%])$, solar radiation $\left(R_{s},\left[\mathrm{~W} \mathrm{~m}^{-2}\right]\right)$ and reference evapotranspiration $\left(E T_{o}\right)$ were preliminary selected as explicative variables in the relationship with NTG, since these variables are supposedly those that most influence the occurrence of natural thermal gradients. The

Table 1

Installation details of the sap flow sensors.

\begin{tabular}{llllll}
\hline Sensor & Line & Tree & $\emptyset^{\text {a }}(\mathrm{m})$ & Trunk cross sectional area $\left(\mathrm{m}^{2}\right)$ & Azimuth \\
\hline G1 & 16 & 34 & 0.075 & 0.004 & $\mathrm{NE}$ \\
G2 & 16 & 36 & 0.054 & 0.002 & $\mathrm{~W}$ \\
G3 & 16 & 38 & 0.080 & 0.005 & $\mathrm{E}$ \\
G5 & 16 & 43 & 0.072 & 0.004 & $\mathrm{NW}$ \\
G6 & 16 & 44 & 0.074 & 0.004 & $\mathrm{NE}$ \\
G7 & 13 & 38 & 0.071 & 0.004 & $\mathrm{E}$ \\
G8 & 13 & 39 & 0.078 & 0.005 & $\mathrm{~N}$ \\
G10 & 13 & 42 & 0.079 & 0.005 & $\mathrm{~S}$ \\
GN & 13 & 41 & 0.076 & 0.005 & $\mathrm{E}$
\end{tabular}

a Trunk diameter at $30 \mathrm{~cm}$ height.

b Heater switched off. 
relation between $R_{S}, T, R H$ and the NTG was studied through linear regression models. However, the model NTG $=0.32-0.60 R_{s}-0.37$ $R H\left(r^{2}=0.72\right)$ presented the most adequate relation to estimate NTG, meaning that $72 \%$ of events were explained by the model at the $5 \%$ significance level. The remaining models were not significant. The criteria for the selection of the explicative variables were based on the analysis above mentioned, thus the explicative variables solar radiation and relative humidity have been selected.

The values of $\Delta T$ were obtained by 9 sensors (G1, G2, G3, G5, G6, G7, G8, G10 and GN) installed in olive trees just below the bark, with a distance of $10 \mathrm{~cm}$ between heated and unheated gauges ( $\mathrm{Ta}-$ ble 1) ( $1 \mathrm{~cm}$ probes from UP GmbH, Germany). The reference sensor (GN) has traced the temperature variability (NTG) into the trunk when the heater was switched off. Mean sap flow data was stored every $30 \mathrm{~min}$ in a datalogger (Model CR1000, Campbell Scientific, Inc., Logan, UT, USA).

Three $\Delta T$ approaches were used in function of the variable time $(t,[s])$ :

$\Delta T_{a d j(t)}=\Delta T_{(t)}-\mathrm{NTG}_{o b s(t)}$

$\Delta T_{n a(t)}=\Delta T_{(t)}$

$\Delta T_{\operatorname{pred}(t)}=\Delta T_{(t)}-\mathrm{NTG}_{\operatorname{pred}(t)}$

where $\Delta T_{(t)}$ is the temperature difference acquired by the sensor when switched ON at $t$ time, $\Delta T_{\operatorname{adj}(t)}\left[{ }^{\circ} \mathrm{C}\right]$ is the $\Delta T$ adjusted by the natural temperature gradient observed at $t$ time, which $\mathrm{NTG}_{o b s(t)}$ $\left[{ }^{\circ} \mathrm{C}\right]$ is acquired by the reference sensor GN when switched OFF, $\Delta T_{n a(t)}\left[{ }^{\circ} \mathrm{C}\right]$ is the $\Delta T$ not adjusted, $\Delta T_{\operatorname{pred}(t)}\left[{ }^{\circ} \mathrm{C}\right]$ is the $\Delta T$ adjusted by the NTG predicted via algorithm at $t$ time $\left(\mathrm{NTG}_{\text {pred }(t)}\right)$.

To accurately calculate the sap flux, the basic term $\Delta T_{\max }$ must be determined separately for each sensor (Granier, 1987). Two estimates of $\Delta T_{\text {max }}$, i.e., $\Delta T_{\text {max_adj }}$ and $\Delta T_{\text {max } \_ \text {na }}$ were calculated for each sensor by searching the maximum temperature difference obtained with a sensor switched ON (heated) over the initial 10 days.

Accordingly, by Eqs. ((1)-(3)) and for each sensor, the values of $k$, sap flux density $\left(u\left[\mathrm{~m}^{3} \mathrm{~m}^{-2} \mathrm{~s}^{-1}\right]\right)$ and sap flux rate $\left(F\left[\mathrm{~m}^{3} \mathrm{~s}^{-1}\right]\right)$ were obtained by range of temporal sequence (Fig. 1), namely $k$, $u$ and $F$ adjusted $\left(k_{a d j}, u_{a d}\right.$ and $\left.F_{a d j}\right)$, not adjusted $\left(k_{n a}, u_{n a}\right.$ and $\left.F_{n a}\right)$ and predicted ( $k_{\text {pred }}, u_{\text {pred }}$ and $\left.F_{\text {pred }}\right)$.

The temporal sequence of data collected from sensors in the interval DOY (day of year) $[100,160]$ was divided into learning time and forecasting time. The learning time operation was defined as the time used for capturing inferences by generated fuzzy rules.
Table 2

Maximum not adjusted temperature difference $\left(\Delta \operatorname{Tmax\_ na}\left[{ }^{\circ} \mathrm{C}\right]\right)$ and Maximum adjusted temperature difference $\left(\Delta \operatorname{Tmax} \_a d j\left[{ }^{\circ} \mathrm{C}\right]\right)$ obtained from measurements in the 10 initial days (DOY[100,110]).

\begin{tabular}{llll}
\hline Sensor & $\Delta T_{\text {max_na }}$ & $\Delta T_{\text {max_adj }}$ & $\left|\Delta T_{\text {max_na }}-\Delta T_{\text {max_adj }}\right|$ \\
\hline G1 & 11.740 & 11.408 & 0.332 \\
G2 & 14.880 & 14.551 & 0.329 \\
G3 & 13.510 & 13.254 & 0.256 \\
G5 & 13.260 & 12.984 & 0.276 \\
G6 & 11.990 & 11.705 & 0.285 \\
G7 & 11.660 & 11.314 & 0.346 \\
G8 & 14.140 & 13.942 & 0.198 \\
G10 & 10.790 & 10.397 & 0.393 \\
\hline
\end{tabular}

Alternatively, the forecasting time operation was defined as the time used in estimating NTG occurrences when environmental variables and fuzzy rules were generated. The learning time and the forecasting time are illustrated in Fig. 1.

The $\Delta T_{\text {max } \_ \text {na(t) }}$ and $\Delta T_{\text {max_adj }}$ were extracted from the sensor's measurements in the 10 initial days (Table 2) and recorded for later computations. Lastly, FAUSY started the forecasting time process by estimating $k$ through $\Delta T_{\text {pred(t) }}$ and $\Delta T_{\text {max_adj, }}$, for all sensors.

\subsection{Development of the fuzzy algorithm}

\subsubsection{Knowledge base and data base}

The Fuzzy Algorithm Automation System (FAUSY) is structured in two modules: (a) knowledge base and database, and (b) inferential machine (Fig. 2). The SWI-PROLOG computational environment was used for practical implementation of the FAUSY algorithm given its easy installation and use because it does not require an ample knowledge in programming and is freely available (Wielemaker et al., 2012).

The knowledge base was adequately represented by a fuzzy logic approach, which provides a computational framework for fuzzy inference in an environment of approximate information. It was used to define and qualify parameters that describe relationships in each event. The knowledge base was prepared aiming to supply information about the discretization and fuzzification processes.

The database is set as a structured collection of data. Data, i.e., input/output events, are registered and recorded into a database by the algorithm. These records were treated as unsupervised learning. The term unsupervised learning is used as referring to automatically mapping of an input-output event's vector into

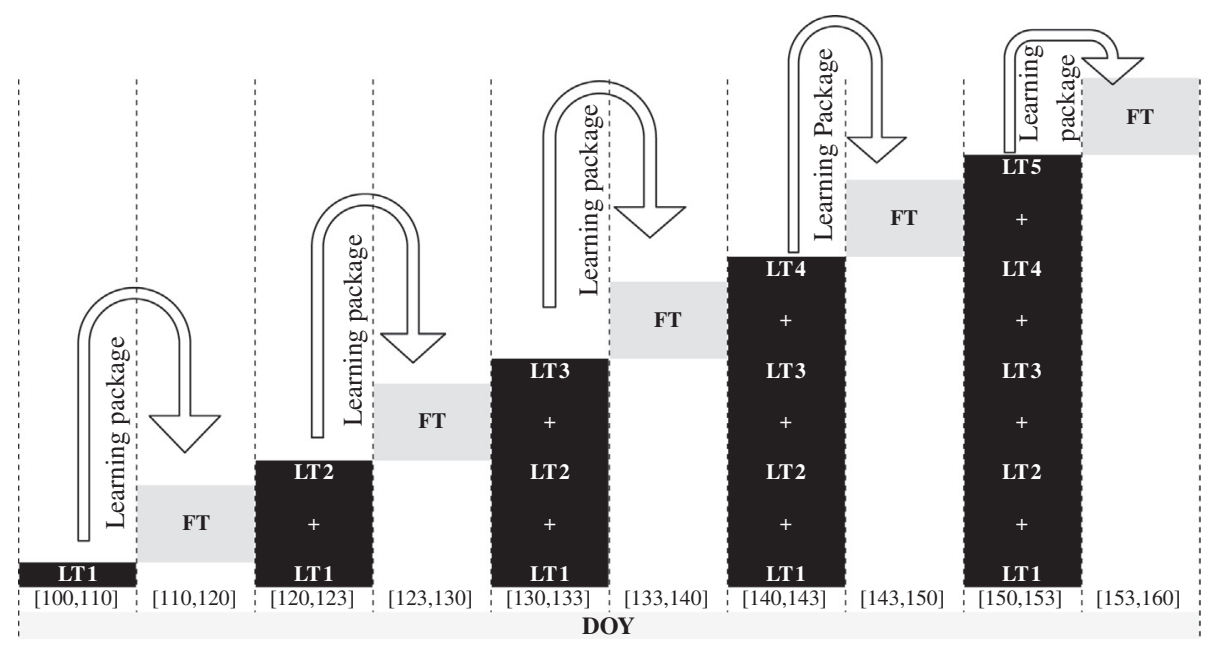

Fig. 1. Learning time (LT) and forecasting time (FT) temporal sequence of data collected from sensors in interval Day of Year (DOY) [100,160]. 


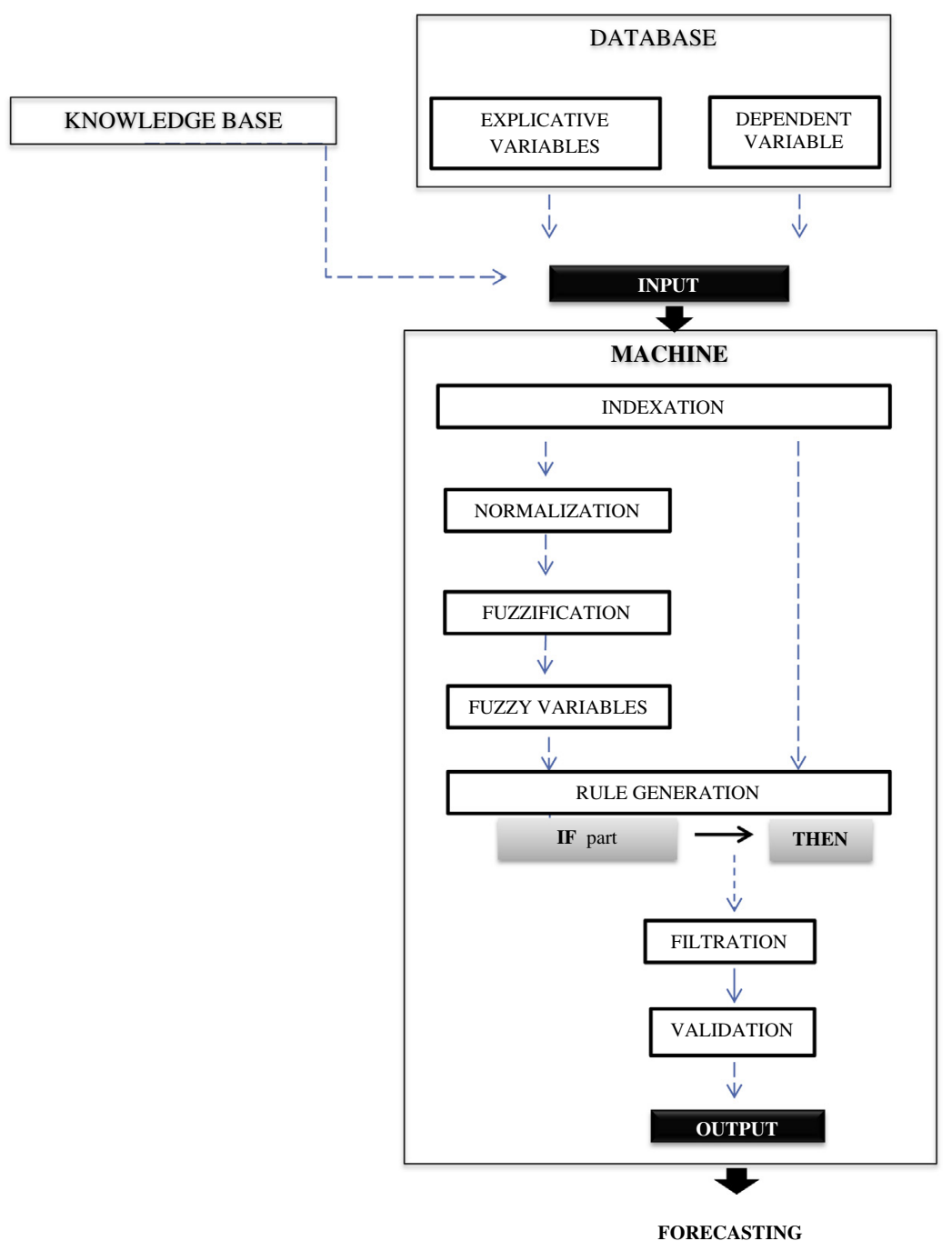

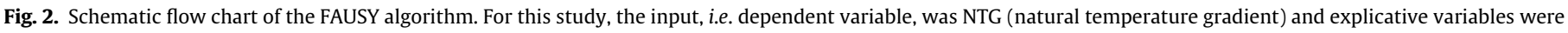
solar radiation, relative humidity and reference evapotranspiration. The outputs were learned and predicted temperature difference values.

classes and building systematic learning, i.e., generating rules mechanically.

\subsubsection{Inferential machine}

The inferential machine comprises the procedural steps in the learning time and the generation of output, in the forecasting time. Five steps are operated in learning time.

2.2.2.1. Step 1: data processing. The database is composed by two categories of variables, explicative and dependent, and supplied by inputs per Day of Year (DOY). All input values - explicative variables $(V)$ and dependent variables $(\mathrm{Vd})$ are indexed. The input dataset indexed should guarantee correct matching between inputs in the time line and avoid computational effort in the fuzzification stage.

The dependent variable NTG has arisen from sensor reference measurements. The explicative variables solar radiation $\left(R_{S}\right)$ and relative humidity $(R H)$ are selected from meteorological observations. The explicative variable time is discrete within the interval $[1,48]$ which means one unit each $1 / 2$ hour, in one day. Otherwise, the continuous explicative variables should be normalized. The normalization of the database causes a fine-tuning in the fuzzy rules generation (El-Shafie et al., 2011) since assuming a relative magnitude for variables clarifies the comparison process. The explicative variable Time (fraction of day: $1 / 48,12 / 48, \ldots, 48 / 48$ ) was selected and associated to each NTG of the switched off reference sensor GN. This means that the input values of continuous variables are normalized into an appropriate scale defined by the maximum and minimum values by,

$x_{n}=\left(x-x_{\min }\right) /\left(x_{\max }-x_{\min }\right)$

where $x_{n}$ is the normalized value, $x$ is the actual value, and $x_{\text {min }}$ and $x_{\max }$ are the minimum and maximum values of $x$ in the actual series. In case information about $x_{\min }$ and $x_{\max }$ is lacking, they should be estimated from the empirical knowledge on the range of these variables. Thus, the $R_{S}$ and $R H$ attributes were normalized into a real number in the unit interval $[0,1]$.

2.2.2.2. Step 2: Fuzzification. Automatic generation of fuzzy rules is based on the fuzzification procedure, in which the input values, supplied in a digital form, are converted to labelled values associated at degree of membership, namely, fuzzy variables or linguistic variables. These linguistic variables are combined to generate fuzzy rules in accordance with the objective of the system, that are casually delivered to other system devices.

The fuzzification procedure consists of the universe of discourse (UD) of continuous explicative variables being divided into fuzzy regions. The UD is divided into a number of overlapping (fuzzy) 
regions and, to each region, a triangular membership function $\left(f_{\Delta j}\right)$ is defined. The number of fuzzy regions $\left(n_{f r}\right)$, which are overlapped sets of variables, are quantified by $n_{f r}=2 N+1$, where $N$ is an adequate numerical choice that ensures an odd number for $n_{f r}$, with a central region. The accuracy of the algorithm can be regulated through an adequate choice of $N$, since larger values generally imply higher accuracy levels.

The simple triangular membership function $\left(f_{\Delta j}\right)$ is easily computed as,

$F_{\Delta j}\left(x_{i}, a_{j}, b_{j}, c_{j}\right)=\mathrm{FS}_{\mathrm{j}}\left(x_{i}\right)= \begin{cases}0 & x_{i}<a_{j} \\ \left(x_{i}-a_{j}\right) /\left(b_{j}-a_{j}\right) & a_{j} \leqslant x_{i} \leqslant b_{j} \\ \left(c_{j}-x_{i}\right) /\left(c_{j}-b_{j}\right) & b_{j} \leqslant x_{i} \leqslant c_{j} \\ 0 & x_{i}>c_{j}\end{cases}$

where $a_{j}$ and $c_{j}$ are defined by a lower limit of membership with $a_{j}<c_{j}, b_{j}$ is defined by an upper limit of membership, and $x_{i}$ is the input value to fuzzification. The parameters $a_{j}, b_{j}$ and $c_{j}$ of a triangular membership function for the $j$ th fuzzy set $\left(\mathrm{FS}_{\mathrm{j}}\right)$ can be calculated by:

$b_{1}=0, b_{2}=b_{1}+1 /\left(n_{f r}-1\right), \ldots, b n_{f r}=b n_{f r-1}+1 /\left(n_{f r}-1\right)$

$a_{i}=b_{i}-1$

$c_{i}=b_{i}+1$

with the domain interval of $\mathrm{FS}_{\mathrm{j}}[0 ; 1]$ divided into $\left(n_{f r}-1\right)$ equal regions. The information on parameters $a_{j}, b_{j}$ and $c_{j}$ of the function (8) should be included in the knowledge base.

2.2.2.3. Step 3: Fuzzy rule generation. After the fuzzification procedure, the fuzzy rule generating algorithm can be executed. The absolute target is developing a fuzzy model that is capable of learning and afterwards forecasting the dependent variables of a given input set in real time by the fuzzy inferential mapping (Bisht et al., 2009) as

\section{IF part Inference operator THEN part}

The fuzzy-rules generation algorithm is computed at the learning time and is based on multi-input/single-output events in the rule matrix.

rule matrix $=\left|\begin{array}{llll}\mathrm{IF} & \cdots & \mathrm{IF} & \mathrm{THEN} \\ \vdots & & \vdots & \vdots \\ {[\mathrm{FV}]_{l}^{e}} & \cdots & {[\mathrm{FV}]_{l}^{e}} & {[\mathrm{Vd}]_{e \times l+1}^{e}}\end{array}\right|$

In the rule matrix, each column IF represents the inputs of the $i$ explicative fuzzy variables (FV) and the single column THEN is the output Vd relative to each event $e$. Each row characterizes a generated rule, which is recorded to be later filtered as referred below. Occasionally, it is possible that some situations do not occur in the learning time but arise only in the forecasting time. This may result from learning directly from environmental variables that behave as non-continuous functions. In this case, the algorithm FAUSY will do the learning considering directly the explicative variable Time to fill in the gap of the non-continuous function and not the function itself.

2.2.2.4. Step 4: Filtering. Conflicting situations can arise when rules with the same antecedents, i.e. the same IF parts, but different consequents (the THEN parts) are generated. In case of a conflict situation, Wang and Mendel (1992) suggested that a degree of membership should be assigned to each rule and that the conflicting rules with the highest degree should be retained and the other ones rejected. However, because all rules generated are information, rejects are not possible. Vojtáš (2001) referred that it is important to have sound and complete semantics because it empowers to compare representative results of computation with real world data. It should be assured that all occurrences must be computed to describe the status quo. Thus, if there are conflicting rules, the model should look for the best solution based in the fuzzy logic theory. In FAUSY the conflicting rules are overcome through calculation of the average of the consequent part. For example, considering two rules:

$\mathrm{FV}_{1} \ldots \mathrm{FV}_{n} \rightarrow \mathrm{Vd}_{x}$

$\mathrm{FV}_{1} \ldots \mathrm{FV}_{n} \rightarrow \mathrm{Vd}_{y}$

where the aforementioned consequent part is $\mathrm{Vd}_{x} \neq \mathrm{Vd}_{y}$, the average of the rule pair is calculated as

$\mathrm{Vd}_{x, y}=\left(\mathrm{Vd}_{x}+\mathrm{Vd}_{y}\right) / 2$

2.2.2.5. Step 5: Performance assessment. The FAUSY algorithm should identify the explicative variables, selected for fuzzy rules set generation, better related to NTG. The performance assessment is done by analysing the residual error (RE) between the predicted and observed values of the dependent variable and through the mean square error (MSE). RE refers to the discrepancy between the observed and predicted outputs (i.e., $\mathrm{NTG}_{o b s(t)}$ and $\mathrm{NTG}_{\text {pred(t) }}$ ):

$\mathrm{RE}=\left|\widehat{Y}_{i}-Y_{i}\right|$

where $Y_{i}$ is $\mathrm{NTG}_{\text {obs }(t)}$ and $\widehat{Y}_{i}$ is $\mathrm{NTG}_{p r e d(t)}$ at the $i$ th event. The mean squared error (MSE) is evaluated using the equation:

$\mathrm{MSE}=1 / n \sum_{i=1}^{n}\left(\widehat{Y}_{i}-Y_{i}\right)^{2}$

where $n$ is the total number of events in the specific time interval. The selection of the best explicative variables set will be defined by the minimum MSE.

If a large residual error occurs, then the first set of generated rules in the learning time is not sufficient to explain the reasoning of the system, or a weak relation was established between the explicative variables and the NTG observed. Therefore, the learning time should be larger, or the explicative variables should be replaced by new generated fuzzy rules. The decision on how to proceed should be taken by the expert; thus the expert's information should be added into the knowledge base. In addition, if the magnitude of the residual error is very small, then it is adequate to initiate the forecasting time implementation, which works following the last event in $t$ learning time when learned with the explicative variables.

\subsection{Methodology for performance evaluation of FAUSY}

The performance evaluation of FAUSY algorithm is achieved using the following residual error equations

$\mathrm{RE}_{\mathrm{f}}=\left|F_{\text {pred }}-F_{a d j}\right|$
$\mathrm{RE}_{\mathrm{na}}=\left|F_{n a}-F_{a d j}\right|$
$\mathrm{PFC}=\left(\mathrm{RE}_{\mathrm{f}}-\mathrm{RE}_{\mathrm{na}}\right) 100 / \mathrm{RE}_{\mathrm{na}}$

where $R E_{f}$ and $R E_{n a}$ are the residual errors obtained when comparing the results of the sap flux rate predicted respectively by the FAUSY algorithm $\left(F_{\text {pred }}\right)$ and the sap flux rate not adjusted $\left(F_{n a}\right)$ with the sap flux rate manually adjusted $F_{a d j}$. PFC is the percentage of FAUSY contribution to the improvement of sap flux rate estimation without requiring manual computations.

The performance evaluation through the $\mathrm{RE}_{\mathrm{f}}, \mathrm{RE}_{\mathrm{n}}$ and PFC calculations infer if the FAUSY algorithm contributes to the $\Delta T$ adjust- 


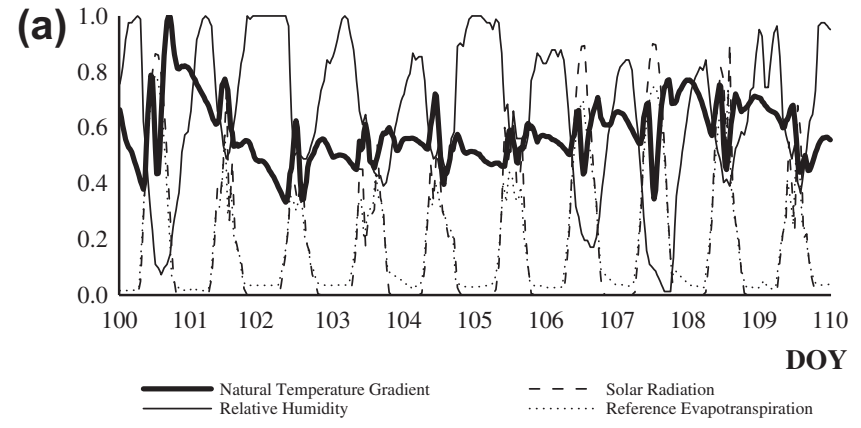

(b)

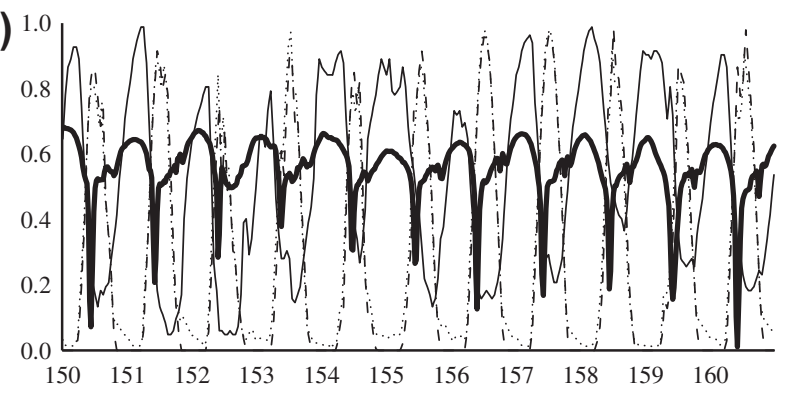

DOY

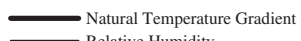

- - - Solar Radiatio

Reference Evapotranspiration

Fig. 3. Visual analysis of daily behaviour of natural temperature gradients and the accessible explicative variables (normalized data) in equal time line, namely, reference evapotranspiration $\left(E T_{o}\right)$, solar radiation $\left(R_{S}\right)$ and relative humidity $(R H)$ over (a) $[100,110]$ and (b) $[150,160]$.

ment and if it can supplant the non-automatic data processing when the sensor is switched on. The non-automatic data processing is less advantageous since it is a procedure in which the $k$ value is computed after the complete data sets (relative to each sensor and for the periods between data collection events) have been obtained.

\section{Results and discussion}

\subsection{Setting parameters}

The search space of the learning parameters is potentially very large, as a countless number of associations can be performed between environmental parameters and different learning time steps. Thus it was essential to set parameters in accordance with the knowledge base and observations. In view of this, it was observed (Fig. 3A and B) that potential relationships, could be established over the DOY intervals $[100,110]$ and $[150,160]$ between the natural temperature gradients (NTG) and the explicative variables available, namely reference evapotranspiration $\left(E T_{o}\right)$, solar radiation $\left(R_{s}\right)$ and relative humidity $(R H)$. These time intervals were selected from several intervals established for learning time to show the unpredictability of the process. However, the relationship was better between the NTG and the variables $E T_{o}, R_{s}, R H$ at time interval $[150,160]$, than at time interval $[100,110]$. This corroborates the need of a phased learning time procedure (Fig. 1), aiming to attenuate the unpredictability over time. Following this first assessment, the fuzzy rules were generated considering the relationship between the variables $E T_{o}, R_{S}$ and $R H$ and NTG, for the time interval $[100,110]$, being the next step the search for the best related variable.

The deviations of environmental variables, namely $R_{s}$ and $R H$, when related to NTG (Fig. 3) showed a minor residual error when compared with the $E T_{o}$ variable (Fig. 4). The reason arises probably from the fact that although $E T_{o}$ integrates the same meteorological information, it also integrates biophysical plant parameters, however relative to grass, the reference crop considered, different from the parameters of the crop under study. The NTG development, in its turn, is influenced by the effect of tree shadowing and row orientation of the crop, with shadow changing over the day, thus dynamically modifying the NTG value near the probes. This supports the observed fact that NTG forecasting related to $E T_{o}$ is undefined and that the fuzzy rules associated with the explicative variables $\left(R_{s}\right.$ plus $\left.R H\right)$, by themselves, show the best fitting.

In time interval $[100,110]$, FAUSY searched for relationships between the available explicative variables and the dependent variable NTG. After comparing the residual error values, it was verified that the rules generated with $R_{S}$ and $R H$ led to smaller absolute average residual errors than the rules generated with $E T_{o}$ (Fig. 4), respectively 0.0551 and 0.0996 . Therefore, $R_{s}$ and $R H$ have been adopted to predict the NTG values.

In the next step, three categories of $t$ time variable combinations, i.e., combinations between explicative variables $R_{S}$ and $R H$ were set: $(t-4),(t-2)$ and $(t)$ steps backward over time (SBT). SBT means the collected data in different time, i.e., the algorithm searches for data four, two or zero steps backward from $t$ time. For example, if the algorithm picks the values for $R_{s}$ and $R H$, for time $t$ and time $t-4$, this variable combination is described as $R_{s(t-4)} \times R_{s(t)} \times R H_{(t-4)} \times R H_{(t)}$. During $[100,110]$, an increasing

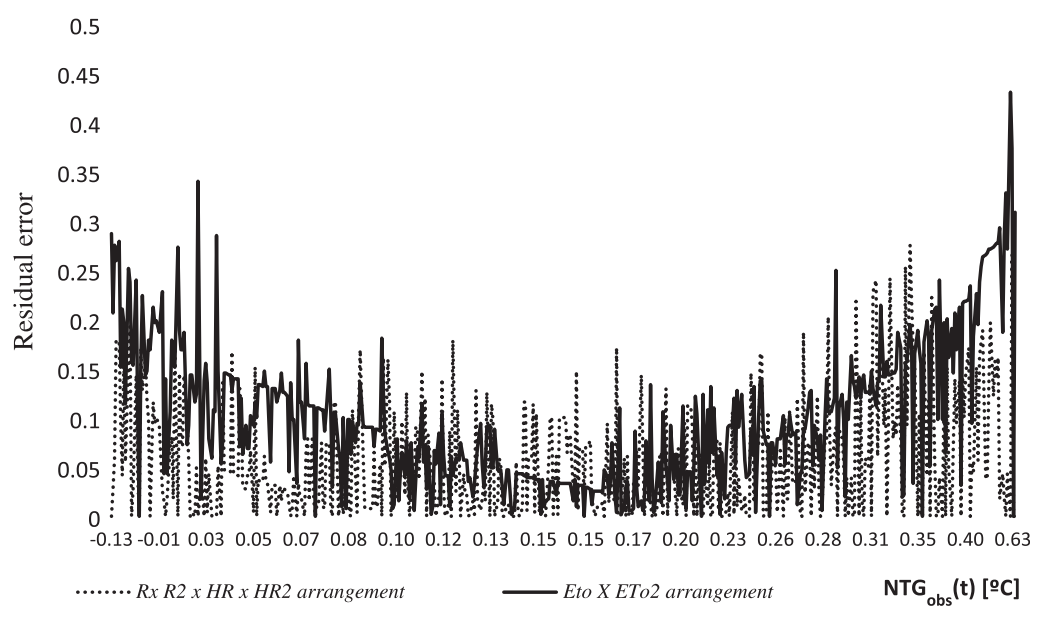

Fig. 4. Comparing the residual error obtained for the $R_{s(t-2)} \times R_{s(t)} \times R H_{(t-2)} R H_{(t)}$ and the $E T_{o(t-2)} \times E T_{o(t)}$ variable combinations. 
Table 3

Mean squared error of the four variable combinations during the period DOY 100, 110 (learning time).

\begin{tabular}{ll}
\hline Variable combinations & MSE \\
\hline$R_{s(t-4)} \times R_{s(t)} \times R H_{(t-4)} \times R H_{(t)}$ & 0.0021 \\
$R_{s(t-2)} \times R_{s(t)} \times R H_{(t-2)} \times R H_{(t)}$ & 0.0030 \\
$R_{s(t)} \times R H_{(t)}$ & 0.0060 \\
$E T_{o(t-2)} \times E T_{o(t)}$ & 0.0099 \\
\hline
\end{tabular}

MSE was observed for the variable combinations: $R_{S(t-4)} \times$ $R_{s(t)} \times R H_{(t-4)} \times R H_{(t)} ; \quad R_{s(t-2)} \times R_{s(t)} \times R H_{(t-2)} \times \mathrm{RH}_{(t)} ; \quad R_{s(t)} \times R H_{(t)}$ and $E T_{o(t-2)} \times E T_{o(t)}$ (Table 3). The variable combination $R_{s(t-4)} \times R_{s(t)} \times R H_{(t-4)} \times R H_{(t)}$ produced the lowest MSE (about $0.0021)$ for $[100,110]$; hence this variable combination was chosen for learning time, as soon as the sensor was switched off (without heating).

\subsection{Comparison between manual and fuzzy logic data treatments}

FAUSY results were compared with those obtained with manually processed data. In the time interval $[110,160]$, the performance of FAUSY algorithm was analysed by residual error Eqs. ((19)-(21)). The average values of residual errors, for FAUSY treatment or without any correction for NTG $\left(R E_{f}, R E_{n a}\right.$, respectively) are shown in Table 4, as well as the improvement obtained with FAUSY (PFC). The residual error observed in all sensors showed lower residual error $\left(R_{f}\right)$, when compared to the not adjusted procedure $\left(R E_{n a}\right)$. The FAUSY algorithm simulated the sap flux rate of sensors with a mean residual error of $0.028 \mathrm{~mm} \mathrm{~d}^{-1}$, lower than the mean residual error of sap flux rate obtained without NTG corrections (using $\Delta T_{n a(t)}$ ), which was about $0.12 \mathrm{~mm} \mathrm{~d}^{-1}$. PFC indicated an acceptable improvement when using the FAUSY algorithm comparatively to the situation of no NTG correction $(76.14 \%$, where $100 \%$ represents the manual NTG correction), meaning that the algorithm is potentially advantageous for daily sap flow rate estimations.

The best results for daily transpiration $\left[\mathrm{mm} \mathrm{d}^{-1}\right]$, when comparing manual with FAUSY data treatment, were found for sensor G7, with a PFC equal to $86.67 \%$ (Fig. 5a).The sensor G8 showed the worst adjustment, with a PFC of $18.18 \%$ (Fig. 5b). Results for sensor G5 have shown an intermediary behaviour, with $\mathrm{PFC}=66.29 \%$ (Fig. 5c). These dissimilarities are explicated by Table 2, which presents the difference between $\Delta T_{\text {max_adj }}$ and $\Delta T_{\text {max_na }}$ showing that sensor G8 had the smallest difference and sensor G7 the largest. It corroborates the fact that the biased $\Delta T_{\max }$ values are propagated in the $k$ calculations. Thus, the magnitude of adjustment of $\Delta T_{\max }$ is proportional to the magnitude of $\Delta T$ adjustment and, consequently, to the $k$ calculations. Furthermore, $\Delta T_{\text {max_adj }}$ has been used to calculate $k$ adjusted predicted ( $k_{\text {pred }}$ ) and therefore, FAUSY uses information in the initial learning time (initial 10 days) to learn
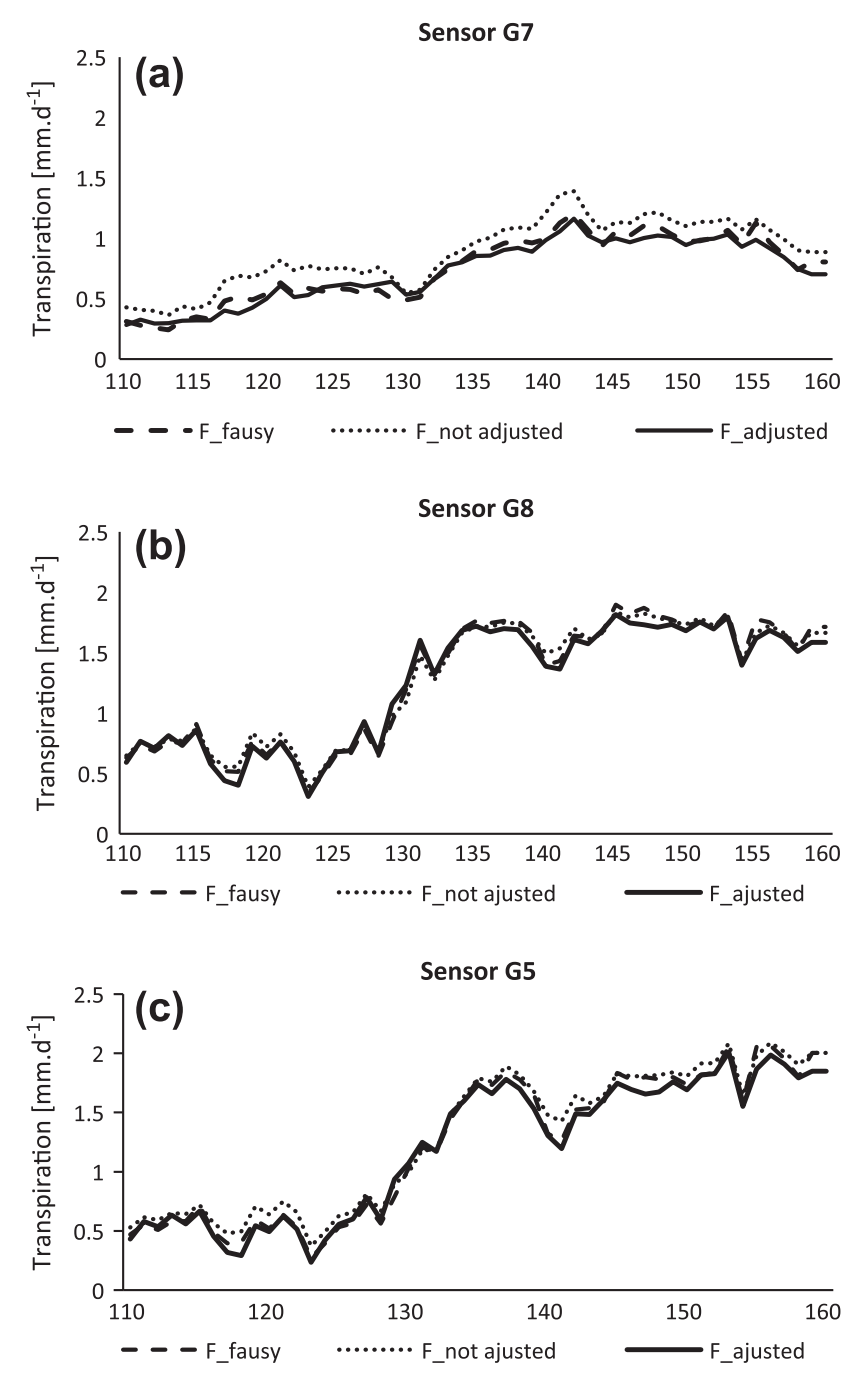

Fig. 5. Comparison of sap flux rate estimates with the FAUSY algorithm, using the not adjusted procedure and the adjusted procedure for sensors (a) G7, (b) G8 and (c) G5.

with explicative variables and obtain an estimate of the $\Delta T_{\max }$ value observed. The differences observed in FAUSY contribution for the different sensors corroborate the fact that NTG are spatially and temporally variable. For that reason, for a more accurate approach, each sensor should use itself as reference sensor, thus switched off in specific periods. This is possible if there is an algorithm (e.g. FAUSY algorithm) capable of replacing the periods when the heater is on. Operating in this mode or after calibration, and in relation to other NTG correction systems, it discards the need for additional equipment (e.g., that needed to shut down the heating

Table 4

Performance of FAUSY algorithm computed by residual error Eqs. ((19)-(21)) computed from mean transpiration [mm $\mathrm{d}^{-1}$ ].

\begin{tabular}{|c|c|c|c|c|c|c|c|}
\hline \multirow[t]{2}{*}{ Sensor } & \multicolumn{3}{|c|}{ Mean transpiration $\left(\mathrm{mm} \mathrm{d}^{-1}\right)$} & \multicolumn{2}{|c|}{ Mean residual error $\left(\mathrm{mm} \mathrm{d}^{-1}\right)$} & \multicolumn{2}{|c|}{ Fausy contribution } \\
\hline & $F_{n a}$ & $F_{a d j}$ & $F_{\text {pred }}$ & $\mathrm{RE}_{\mathrm{na}}$ & $\mathrm{RE}_{\mathrm{f}}$ & $\mathrm{RE}_{\mathrm{f}}(\%)$ & PFC (\%) \\
\hline G1 & 1.831 & 1.672 & 1.718 & 0.159 & 0.046 & 2.75 & 71.07 \\
\hline G2 & 0.594 & 0.500 & 0.514 & 0.094 & 0.014 & 2.80 & 85.11 \\
\hline G3 & 1.215 & 1.139 & 1.155 & 0.076 & 0.016 & 1.40 & 78.95 \\
\hline G5 & 1.259 & 1.170 & 1.200 & 0.089 & 0.030 & 2.56 & 66.29 \\
\hline G6 & 1.120 & 1.022 & 1.054 & 0.098 & 0.032 & 3.13 & 67.35 \\
\hline G7 & 0.861 & 0.711 & 0.731 & 0.150 & 0.020 & 2.81 & 86.67 \\
\hline G8 & 1.246 & 1.213 & 1.240 & 0.033 & 0.027 & 2.23 & 18.18 \\
\hline G10 & 1.703 & 1.459 & 1.499 & 0.244 & 0.040 & 2.74 & 83.61 \\
\hline Mean & 1.23 & 1.11 & 1.14 & 0.118 & 0.028 & 2.53 & 76.14 \\
\hline
\end{tabular}


system periodically or additional unheated probes), relying only on the use of meteorological variables, commonly available on experimental sites.

In a global view of the process, FAUSY contribution to automation could be clearly demonstrated for prompt searching over available explicative variables, returning the lowest residual error possible. This fact corroborates the rapidness of the automation process, since the simple residual error calculation may be accepted as an efficient statistical tool. Additionally, in the manually adjusted procedure, the $k$ calculation was computed after the complete data set has been collected; consequently, it was not possible to compute it in real time. Alternatively, FAUSY routine computed $k$ at the same input data time, after the learning time, which allowed automation and availability in real time. As FAUSY relies only on measureable environmental conditions, it can theoretically be applied to other woody species and different conditions, although it must be more extensively tested, since this is the first application performed and factors influencing NTG (e.g., distance of the sensors from soil, presence/absence of irrigation) can change. The algorithm is also potentially applicable to other sap flow measurement methodologies in order to perform possible adjustments and further automate measurements.

\section{Conclusions}

In the present study, research by fuzzy rules generation was applied to Granier sap flow data treatment. In this context, the FAUSY algorithm shows to be an effective approach for system optimization, contributing positively to the estimation of adjusted $\Delta T$ values corrected for natural temperature gradients, therefore allowing to automate the data analysis process. The use of FAUSY allowed for a less time-consuming process, yet not discarding the human decision capacity, since it mimetizes the process. In addition, it provides the opportunity for earlier reaction to data because it allows for a real-time treatment possibility.

This algorithm consists of an innovative approach for data treatment when using the Granier method for sap flow measurement and allows to overcome the major restrictions of extensive data processing, especially when practical applications in irrigation management are intended. FAUSY algorithm presents a simpler solution to correct NTG in relation to other systems, since it relies only on the use of meteorological variables, commonly available on experimental sites.

In the future, FAUSY algorithm is potentially applicable to other sap flow measurement methodologies and other woody species, although further testing is needed.

\section{Acknowledgements}

This work was supported by the Projects H2Olive3S (PTDC/ AGR-PRO/111717/2009, FCT-Portuguese Foundation for Science and Technology), PEst-OE/AGR/UI0245/20113 (FCT), and Program Ciência 2008 (FCT). The authors also thank the support provided by the farming company "Olivais do Sul" and the Program Science Without Borders (Brazil).

\section{References}

Al-Faraj, A., Meyer, G.E., Horst, G.L., 2001. A crop water stress index for tall fescue (Festuca arundinacea Schreb.) irrigation decision-making - a fuzzy logic method. Comput. Electron. Agric. 32, 69-84.

Allen, R.G., Pereira, L.S., Raes, D., Smith, M., 1998. Crop Evapotranspiration. Guidelines for Computing Crop Water Requirements. FAO Irrig. and Drain. Paper 56, FAO, Rome, 300p.

Allen, R.G., Pereira, L.S., Howell, T.A., Jensen, M.E., 2011. Evapotranspiration information reporting: I. Factors governing measurement accuracy. Agric. Water Manag. 98, 899-920.
Bisht, D., Raju, M., Joshi, M., 2009. Simulation of water table elevation fluctuation using fuzzy-logic and ANFIS. Comput. Model. New Technol. 13, 16-23.

Bush, S.E., Hultine, K.R., Sperry, J.S., Ehleringer, J.R., 2010. Calibration of thermal dissipation sap flow probes for ring- and diffuse-porous trees. Tree Physiol. 30, 1545-1554.

Cabibel, B., Do, F., 1991. Mesures thermiques des flux de sève dans les troncs et les racines et fonctionnement hydrique des arbres. I. Analyse théorique des erreurs sur la mesure des flux et validation des mesures en présence de gradients thermiques extérieurs. Agronomie 11, 669-678.

Casper, M., Gemmar, P., Gronz, O., Johst, M., Stüber, M., 2007. Fuzzy logic-based rainfall - runoff modelling using soil moisture measurements to represent system state. Hydrol. Sci. 52, 478-490.

Cermák, J., Kucera, J., 1981. The compensation of natural temperature gradient at the measuring point during the sap flow rate determination in trees. Biol. Plant. 23, 469-471.

Cermák, J., Deml, M., Penka, M., 1973. A new method of sap flow rate determination in trees. Biol. Plant. 15, 171-178.

de la Torre, M.L., Grande, J.A., Aroba, J., Andujar, J.M., 2005. Optimization of fertirrigation efficiency in strawberry crops by application of fuzzy logic techniques. J. Environ. Monit. 7, 1085-1092.

Delgado, G., Aranda, V., Calero, J., Sánchez-Marañón, M., Serrano, J.M., Sánchez, D., Vila, M.A., 2009. Using fuzzy data mining to evaluate survey data from olive grove cultivation. Comput. Electron. Agric. 65, 99-113.

Do, F., Rocheteau, A., 2002a. Influence of natural temperature gradients on measurements of xylem sap flow with thermal dissipation probes. 1. Field observations and possible remedies. Tree Physiol. 22, 641-648.

Do, F., Rocheteau, A., 2002b. Influence of natural temperature gradients on measurements of xylem sap flow with thermal dissipation probes. 2. Advantages and calibration of a noncontinuous heating system. Tree Physiol. $22,649-654$.

El-Shafie, A., Jaafer, O., Seyed, A., 2011. Adaptive neuro-fuzzy inference system based model for rainfall forecasting in Klang River, Malaysia. Int. J. Phys. Sci. 6, 2875-2888.

Ferreira, M.I., Paço, T.A., Silvestre, J., 2004. Combining techniques to study evapotranspiration in woody crops: application to small areas - two case studies. Acta Hort. 664, 225-232.

González-Altozano, P., Pavel, E.W., Oncins, J.A., Doltra, J., Cohen, M., Paço, T., Massai, R., Castel, J.R., 2008. Comparative assessment of five methods of determining sap flow in peach trees. Agric. Water Manag. 95, 503-515.

Granier, A., 1985. Une nouvelle méthode pour la mesure du flux de sève brute dans le tronc des arbres. Ann. Sci. For. 42, 193-200.

Granier, A., 1987. Evaluation of transpiration in a Douglas-fir stand by means of sap flow measurements. Tree Physiol. 3, 309-320.

Granier, A., Bobay, V., Gash, J.H.C., Gelpe, J., Saugier, B., Shuttleworth, W.J., 1990. Vapour flux density and transpiration rate comparisons in a stand of maritime pine (Pinus pinaster Ait.) in Les Landes forest. Agric. For. Meteorol. 51, 309-319.

Gutiérrez, M.V., Harrington, R.A., Meinzer, F.C., Fownes, J.H., 1994. The effect of environmentally induced stem temperature gradients on transpiration estimates from the heat balance method in two tropical woody species. Tree Physiol. 14, 179-190.

Huang, Y., Lan, Y. Thomson, S.J., Fang, A. Hoffmann, W.C., Lacey, R.E, 2010 Development of soft computing and applications in agricultural and biological engineering. Comput. Electron. Agric. 71, 107-127.

Keskin, M.E., Terzi, Ö., Taylan, D., 2004. Fuzzy logic model approaches to daily pan evaporation estimation in western Turkey. Hydrol. Sci. J. 49, 1001-1010.

Kim, Y., Reid, J.F., Zhang, Q., 2008. Fuzzy logic control of a multispectral imaging sensor for in-field plant sensing. Comput. Electron. Agric. 60, 279-288.

Köstner, B., Granier, A., Cermák, J., 1998. Sapflow measurements in forest stands: methods and uncertainties. Ann. Sci. For. 55, 13-27.

Kucera, J., Cermák, J., Penka, M., 1977. Improved thermal method of continual recording the transpiration flow rate dynamics. Biol. Plant. 19, 413-420.

Lu, P., Urban, L., Zhao, P., 2004. Granier's thermal dissipation probe (TDP) method for measuring sap flow in trees: theory and practice. Acta Bot. Sinica 46, $631-$ 646.

Lubczynski, M.W., Chavarro-Rincon, D., Roy, J., 2012. Novel, cyclic heat dissipation method for the correction of natural temperature gradients in sap flow measurements.Part 1.Theory and application. Tree Physiol. 32, 894-912.

Lundblad, M., Lagergren, F., Lindroth, A., 2001. Evaluation of heat balance and heat dissipation methods for sapflow measurements in pine and spruce. Ann. For. Sci. 58, 625-638.

Mustafa, N.B.A., 2009. Agricultural produce Sorting and Grading using Support Vector Machines and Fuzzy Logic. IEEE Int. Conf. Signal Image Process. Appl. (ICSIPA), 391-396.

Nadezhdina, N., Cermak, J., Nadezhdin, V., 1998. Heat field deformation method for sap flow measurements. In: Cermak, J., Nadezhdina, N. (Eds.), Proceedings of the 4th International Workshop on Measuring Sap Flow in Intact Plants. Publishing House of Mendel University, Czech Republic, pp. 72-92.

Nadezhdina, N., Vandegehuchte, M., Steppe, K., 2012. Sap flux density measurements based on the heat field deformation method. Trees - Struct. Funct. 26, 1439-1448.

Odhiambo, L., Yoder, R., 2001. Optimization of fuzzy evapotranspiration model through neural training with input-output examples. Trans. ASAE 44, 16251633.

Paço, T.A., David, T.S., Henriques, M.O., Pereira, J.S., Valente, F., Banza, J., Pereira, F.L., Pinto, C., David, J.S., 2009. Evapotranspiration from a Mediterranean evergreen oak savannah: The role of trees and pasture. J. Hydrol. 369, 98-106. 
Paço, T., Ferreira, M., Rosa, R., Paredes, P., Rodrigues, G., Conceição, N., Pacheco, C., Pereira, L.S., 2012. The dual crop coefficient approach using a density factor to simulate the evapotranspiration of a peach orchard: SIMDualKc model versus eddy covariance measurements. Irrig. Sci. 30, 115-126.

Passam, H., Tocatlidou, A., Mahaman, B., 2003. Methods for decision making with insufficient knowledge in agriculture. In: EFITA 2003 Conference. pp. 727-731.

Regalado, C.M., Ritter, A., 2007. An alternative method to estimate zero flow temperature differences for Granier's thermal dissipation technique. Tree Physiol. 27, 1093-1102.

Rosa, R.D., Paredes, P., Rodrigues, G.C., Alves, I., Fernando, R.M., Pereira, L.S., Allen, R.G., 2012. Implementing the dual crop coefficient approach in interactive software. 1. Background and computational strategy. Agric. Water Manag. 103, $8-24$.

Silva, R.M., Paço, T.A., Ferreira, M.I., Oliveira, M., 2008. Transpiration of a kiwifruit orchard estimated using the Granier sap flow method calibrated under field conditions. Acta Horticult 792, 593-600.

Siqueira, J., Rocio, V., 2011. Sistema pericial em prolog no diagnóstico do potencial agrícola de solos. In: VI Congresso Ibérico de Agro-Engenharia, Universidade de Évora, CD-Rom paper.

Tatarinov, F.A., Kucera, J., Cienciala, E., 2005. The analysis of physical background of tree sap flow measurement based on thermal methods. Meas. Sci. Technol. 16, 1157-1169.
Tzimopoulos, C., Mpallas, L., Papaevangelou, G., 2008. Estimation of evapotranspiration using fuzzy systems and comparison with the BlaneyCriddle method. J. Environ. Sci. Technol. 1, 181-186.

Valancogne, C., Granier, A., 1997. Mésures de flux de sève brute. In: Riou, C. Bonhomme, R., Chassin, P., Neveu, A., Papy, F. (Eds.), L'eau dans l'espace rural Production végétale et qualité de l'eau. INRA, Paris, pp. 153-160.

Vandegehuchte, M., Steppe, K., 2013. Sap-flux density measurement methods: working principles and applicability. Funct. Plant Biol. 40, 213-223.

Vojtáš, P., 2001. Fuzzy logic programming. Fuzzy Sets Syst. 124, 361-370.

Wang, L.-X., Mendel, J.M., 1992. Generating fuzzy rules by learning from examples. IEEE Trans. Syst. Man Cybern. 22, 1414-1427.

Wielemaker, J., Schrijvers, T., Triska, M., Lager, T., 2012. SWI-Prolog. Theory Practice Logic Program. 12, 67-96.

Zadeh, L., 1965. Fuzzy sets. Inf. Control 8, 338-353.

Zadeh, L., 1968. Fuzzy algorithms. Inf. Control 12, 94-102.

Zadeh, L.A., 1973. Outline of a new approach to the analysis of complex systems and decision processes. IEEE Trans. Syst. Man Cybern. 3, 28-44.

Zadeh, L.A., 2009. Toward extended fuzzy logic - a first step. Fuzzy Sets Syst. 160 3175-3181. 